\title{
BLIND CODE PADA UANG KERTAS RUPIAH PESAN KOMUNIKASI DAN KOMUNIKASI PESAN KEPADA PUBLIK DISABILITAS NETRA
}

\section{BLIND CODE ON RUPIAH BANKNOTES COMMUNICATION MESSAGES AND MESSAGES COMMUNICATION TO THE PUBLIC WITH VISUAL IMPAIRMENTS}

\author{
${ }^{1}$ Hanny Hafiar, ${ }^{* 2}$ Yanti Setianti, ${ }^{3}$ Priyo Subekti, dan Anwar Sani ${ }^{4}$ \\ Universitas Padjadjaran
}

Submitted: 19-08-2019; Revised: 10-11-2020; Accepted:10-11-2020

\begin{abstract}
Recognizing the nominal on banknotes is one of the competencies that must be reached by the community. Eventhough rupiah banknotes have been equipped with blind codes (special markers for the visually impaired), for people with visual impairments, especially children, recognizing nominal banknotes become unique and special challenges and obstacles. The purpose of this research is to map the obstacles faced by the blind when recognizing nominal rupiah banknotes. This research uses descriptive case study method, with a single case. Data collection was carried out by means of observation, focus group discussions, and documentation studies. The sampling technique was conducted purposively on the population that participated in the implementation of blind code socialization activity for persons with visual impairments. The socialization activity presented speakers from Bank Indonesia (Bank of Indonesia) and took place at SLBN A, Bandung. The results of the constraints mapping indicate that differences in paper sizes for various nominals on rupiah banknotes, add new challenges for the participants. Other than that, the types of paper are easily worn, the use of Blind code varies on several emissions, and the existence of Blind code less assertive when touched. The Intaglio (the printmaking technique) often obscure concentration of people with visual impairment in searching for blind code. Other markers such as relatively similar colors and images, also considered less easy for people with visual impairments to recognize banknotes, especially in a rushed transaction.
\end{abstract}

Keywords: Blind code; Nominal banknotes; Visual impairments.

\begin{abstract}
ABSTRAK
Mengenali nominal pada uang kertas merupakan salah satu kompetensi dasar yang harus dimiliki masyarakat. Walaupun uang kertas rupiah sudah dilengkapi dengan blind code (penanda khusus bagi disabilitas netra), namun, bagi sebagian penyandang disabilitas netra, terutama anak-anak yang mengalami hambatan penglihatan, mengenali nominal uang kertas menjadi tantangan unik dan kendala tersendiri. Oleh karena itu tujuan dari riset ini adalah untuk melakukan pemetaan kendala yang dihadapi disabilitas netra saat mengenali nominal uang kertas rupiah. Metode yang digunakan pada penelitian ini adalah metode studi kasus deskriptif, dengan kasus tunggal yang bersifat intrinsik. Pengumpulan data dilakukan, antara lain, dengan cara observasi, focus group discussion, dan
\end{abstract}

${ }^{*}$ Corresponding author: yanti.setianti@unpad.ac.id.

Copyright@ 2020 THE AUTHOR (S). This article is distributed under a Creative Commons Attribution-Share Alike 4.0 International license. Jurnal Kawistara is published by the Graduate School of Universitas Gadjah Mada 
studi dokumentasi. Teknik penentuan sampel dilakukan secara purposif terhadap populasi yang menjadi peserta pada pelaksanaan kegiatan sosialisasi blind code bagi penyandang disabilitas netra. Kegiatan ini menghadirkan pembicara dari pihak Bank Indonesia, dan berlokasi di SLBN A Kota Bandung. Adapun hasil pemetaan kendala menunjukkan bahwa perbedaan ukuran kertas untuk berbagai nominal pada uang kertas rupiah memberikan tantangan tersendiri bagi penyandang disabilitas netra. Selain itu, jenis kertas yang mudah lusuh, penggunaan blind code yang bervariasi pada beberapa emisi, keberadaan Blind code yang kurang tegas saat dilakukan perabaan, intaglio penanda lain acap kali mengaburkan konsentrasi penyandang disabilitas netra dalam mencari blind code. Warna dan gambar yang relatif mirip juga dianggap kurang memudahkan upaya penyandang disabilitas netra dalam mengenali uang kertas pada konteks transaksi yang membutuhkan waktu singkat.

Kata Kunci: Blind code; Nominal uang kertas; Hambatan penglihatan.

\section{PENGANTAR}

Penyandang disabilitas netra, atau yang dikenal sebagai orang yang mengalami hambatan penglihatan, kerap kali mengalami kendala saat mengenali nominal pada uang kertas rupiah. Kondisi hambatan penglihatan yang dialami disabilitas netra, terutama yang berada pada kondisi mengalami kebutaan total, membuat mereka terpaksa mengenali uang kertas melalui perabaan. Pada beberapa emisi uang kertas rupiah telah disediakan blind code (penanda khusus pada uang kertas bagi disabilitas netra). Akan tetapi, menurut penuturan salah satu guru yang mengajar di Sekolah Luar Biasa khusus disabilitas netra, masih terdapat disabilitas netra yang mengalami kesulitan untuk membedakan nominal uang kertas rupiah tersebut, seperti yang dituturkan Yuyun, guru di SLBN A Kota Bandung, berikut ini:

"Sampai saat ini, meskipun sudah ada bantuan blind code pada uang kertas rupiah, namun siswa-siswa di sini masih tetap merasa kesulitan untuk mengenali, sehingga masih sering mengandalkan bertanya kepada orang awas di sekitarnya".
Blind code merupakan pesan yang dikomunikasi melalui media uang kertas. Dalam konteks komunikasi, pesan dibangun melalui kode-kode bahasa, yang pada dasarnya adalah produk dari komunikator dan disampaikan kepada komunikan (publik) baik secara langsung maupun melalui media (Purwasito, 2017). Sedangkan media adalah suatu sarana yang menjadi perantara dalam kegiatan komunikasi (Miftah, 2013), sarana penyalur pesan yang disampaikan oleh sumber pesan kepada sasaran atau penerima pesan tersebut (Mahnun, 2012).

Artinya Blind code pada uang kertas rupiah dimaksudkan sebagai kode bahasa yang memuat informasi, termasuk informasi tentang besaran nominal uang, yang tertera pada media berupa uang kertas agar penyandang disabilitas netra mampu memiliki pemahaman yang sama dengan orang lain pada umumnya, dalam mengenali uang kertas. Jika penyandang disabilitas netra mampu mengenali dan memiliki pemaknaan yang sama dalam menangkap informasi simbolik yang tertera pada media uang kertas melalui blind code, maka dapat dikatakan bahwa pesan telah tersampaikan dan dipahami oleh komunikan. Pengenalan penyandang disabilitas terhadap blind code merupakan salah satu tujuan guna meningkatkan kemandirian mereka.

Pada prinsipnya, pencantuman blind code pada uang kertas rupiah dimaksudkan untuk membuka peluang aksesibilitas agar disabilitas netra memiliki kemudahan untuk mengenali dan memiliki kemandirian untuk melakukan transaksi dengan menggunakan uang kertas. Tetapi pada kenyataannya, masih terdapat disabilitas netra yang mengalami kesulitan dalam mengenalinya.

Oleh karena itu, Komunitas Generasi Baru Indonesia atau GenBI, salah satu komunitas yang membantu untuk memberikan informasi tentang kebijakan-kebijakan yang dikeluarkan oleh Bank Indonesia, pernah melakukan kegiatan guna memfasilitasi komunitas disabilitas netra untuk mengenali uang kertas, melalui kegiatan sosialisasi blind code. Sosialisasi diartikan sebagai proses belajar untuk mengenali sesuatu, sehingga terjadi 
pembentukan sikap, sehingga sosialisasi menjadi salah satu faktor yang mempengaruhi pengetahuan seseorang (Abdullah \& Nasionalita, 2018).

Sosialisasi blind code ini dilakukan karena kemampuan ini diperlukan agar teman disabilitas netra bisa mandiri serta tidak menggantungkan orang lain untuk mengetahui keaslian dan nominal rupiah. Terlebih, kebanyakan penyandang disabilitas menyatakan bahwa mereka memiliki minat untuk berwirausaha. Sedangkan peta permasalahan wirausaha, selain berkisar di ranah permodalan, dan pemasaran, juga membutuhkan kompetensi, dan sumber daya manusia, serta keberpihakan pemerintah (Mihradi \& Siregar, 2018). Sehingga sudah sepatutnya, sebelum penyandang disabilitas dibekali dengan beragam keterampilan wirausaha, mereka dibekali terlebih dahulu kompetensi dasar seperti pengenalan nominal uang kertas.

Generasi Baru Indonesia adalah kelompok mahasiswa penerima beasiswa dari Bank Indonesia, yang memiliki program GenBI mengajar, salah satunya dengan cara berbagi pengetahuan dengan siswa SLB tentang ekonomi dan mengenali uang rupiah (Tempo, 2018). Artinya, Bank Indonesia yang menjadi Bank sentral di Indonesia, telah berupaya melakukan kegiatan sosialisasi melalui berbagai afiliasinya guna memberikan pemahaman kepada disabilitas netra untuk dapat mengenali nominal pada uang kertas secara mandiri. Namun jumlah peserta sosialisasi yang terbatas dan tingkat pemahaman komunikan disabilitas netra yang berbeda-beda, tentu menuntut adanya upaya yang lebih efektif agar tujuan utama yaitu memberikan aksesibilitas bagi disabilitas netra dalam mengenali nominal uang kertas dapat terlaksana dengan efektif.

Mengenali nominal dan keaslian uang kertas rupiah bagi disabilitas netra merupakan hal penting dalam meningkatkan kemandirian mereka dalam menjalani kehidupan seharihari,sebab, uang kertas merupakan jenis uang yang paling banyak variasinya dan paling banyak digunakan untuk bertransaksi, dibandingkan uang koin dalam mata uang rupiah. Hal ini dinyatakan dalam sebuah penelitian terdahulu yang menyebutkan bahwa pertukaran moneter yang sukses melibatkan sejumlah keterampilan komponen, yang paling mendasar di antaranya termasuk membedakan antara unit mata uang dan mengidentifikasi nilai masing-masing mata uang (Hanney \& Tiger, 2012). Maka dari itu, kemampuan mengenali nominal uang kertas merupakan kemampuan dasar manusia untuk melakukan transaksi dengan menggunakan uang kertas.

Hasil penelitian lain menyebutkan bahwa transaksi terkait uang merupakan bagian penting dalam aktivitas kehidupan manusia sehari-hari. Dengan mempertimbangkan kondisi orang-orang disabilitas netra, dapat dikatakan agak sulit untuk mengidentifikasi mata uang kertas karena rasanya akan sama saat diraba jika tanpa ada tanda-tanda yang jelas pada uang kertas tersebut. Oleh karena itu, pengenalan nominal uang kertas kepada penyandang disabilitas netra tidak hanya dapat dilakukan dengan pemberian pesan melalui media uang kertas, namun juga perlu dilakukan komunikasi melalui kegiatan sosialisasi. Menurut Myers (2007: 29-34) langkah- langkah dalam mengelola sosialisasi terdiri dari fase pendahuluan, fase antisipasi, fase pertemuan, fase asimilasi, dan fase keluar (Agustiyani, Hafiar, \& Novianti, 2018), yang dimaksudkan untuk membimbing individu ke dalam dunia sosial (Abdullah \& Nasionalita, 2018).

Sosialisasi uang kertas, baik yang menginformasikan tentang nominal maupun keasliannya, memang perlu dilakukan secara intensif. Mengingat hambatan penglihatan yang dialami disabilitas netra dapat menempatkan mereka pada posisi korban, akibat ketidaktahuan atau kesalahan dalam mengenali uang kertas tersebut. Hal ini sudah pasti perlu dihindari dan diantisipasi. Kegiatan antisipasi dapat dilakukan dengan berbagai cara. Mulai dari pihak disabilitas netra yang proaktif mencari informasi dan meningkatkan kompetensi untuk mengidentifikasi, hingga pihak terkait yang secara terus menerus melakukan pemberdayaan hingga para disabilitas netra tersebut mampu mandiri. 
Selama ini, terdapat cara yang berlaku di kalangan disabilitas netra tertentu dalam mengidentifikasi uang kertas. Salah satunya adalah dengan cara melipat uang. Membuat lipatan pada uang, dianggap sebagai salah satu cara mudah dalam mengidentifikasi nominal uang kertas bagi disabilitas netra. Walaupun disabilitas netra tetap harus menggunakan daya ingatnya. Tak ada pedoman baku dalam membuat lipatan-lipatan tersebut. Bentuk lipatan dapat dilakukan sesuai dengan kehendak pemilik uang. Misalnya, jika terdapat tiga lembar nominal uang kertas yang berbeda, maka disabilitas netra cenderung melakukan gaya lipatan yang berbeda bagi ketiga uang tersebut. Sebagai contoh: nominal 100.000 dilipat menjadi persegi empat, nominal 50.000 dilipat membentuk segitiga, dan nominal 20.000 dilipat membentuk persegi panjang dengan ukuran lebih kecil dari aslinya.

Dengan cara tersebut, disabilitas netra dapat membedakan kumpulan uang yang dimilikinya melalui lipatan-lipatan yang telah dibuatnya (Kartunet, 2012). Melipat uang kertas memang menjadi alternatif cara bagi disabilitas netra dalam mengidentifikasi nominal pada uang kertas. Akan tetapi, berdasarkan Undang-undang Nomor 7 Tahun 2011 melipat, mengelem, dan menjepit uang kertas rupiah dengan alat sejenis stapler dapat dikenai ancaman pidana. Oleh karena itu, dibutuhkan upaya lain yang dapat membantu disabilitas netra untuk mengenali uang kertas. Kesulitan mengenali nominal uang kertas, tidak hanya terjadi di kalangan disabilitas netra di Indonesia, sebab secara universal, salah satu masalah yang biasanya dihadapi oleh disabilitas netra adalah nilai uang kertas (Dunai, Pérez, Peris-Fajarnés, \& Lengua, 2017). Berdasarkan permasalahan yang telah diuraikan tersebut, maka tujuan dari artikel ini adalah berupaya untuk melakukan pemetaan mengenai kesulitan yang dihadapi disabilitas netra dalam mengidentifikasi nominal pada uang kertas rupiah.

Terdapat sejumlah riset sebelumnya yang berkaitan dengan identifikasi uang kertas bagi disabilitas netra. Sejumlah riset di berbagai belahan dunia telah berupaya membantu disabilitas netra untuk mampu mengidentifikasi uang kertas, baik aspek nominal maupun keasliannya, dengan menghasilkan alat bantu teknologi untuk mengidentifikasi. Penelitian-penelitian tersebut antara lain: sistem pengenalan mata uang untuk orang buta menggunakan algoritma. (Yousry, Taha, \& Selim, 2018), aplikasi pembaca uang bagi disabilitas netra melalui seluler (Paisios, Rubinsteyn, \& Subramanian, 2012), pengenalan mata uang yang dapat dilakukan melalui ponsel (Singh, Choudhury, Vishal, \& Jawahar, 2014).

Di dalam negeri sendiri, telah terdapat riset sejenis yang melakukan upaya yang sama, yaitu: teknologi visi komputer berbasis kamera dapat membantu orang-orang tunanetra untuk secara otomatis mengenali uang kertas (Hasanuzzaman, Yang, \& Tian, 2011), pembuatan alat identifikasi nominal pada uang kertas untuk membantu tunanetra yang menggunakan Arduino Mega 2560 (Arpianto, Priyatman, \& Suryadi, 2018), serta sistem keaslian dan pendeteksi nominal uang kertas rupiah berbasis Arduino bagi penyandang tunanetra (Ikhsan \& Sari, 2018).

Akan tetapi, perangkat tersebut masih jarang digunakan oleh disabilitas netra. Salah satu alasannya adalah keterbatasan perangkat teknologi yang mereka miliki. Hasilnya, disabilitas netra di Indonesia masih cenderung mengidentifikasi uang kertas dengan cara konvensional meraba, atau bertanya kepada orang awas di sekitarnya. Hal ini tentu tetap menyisakan masalah. Terutama jika disabilitas netra berada di dalam komunitas disabilitas netra, misalnya di sekolah khusus disabilitas netra yang murid-muridnya juga sesama disabilitas netra. Ataupun jika bertanya pada orang awas, maka tidak selamanya orang awas mampu membantu memberikan informasi yang akurat jika ditinjau dari aspek situasi, kondisi, maupun motif dari orang awas yang ditanyai.

Oleh karena itu, meningkatkan kemandirian disabilitas netra dalam mengenali uang kertas melalui blind code yang telah tersedia, tetap diperlukan. Salah satunya dengan cara pemetaan masalah yang dihadapi disabilitas netra dalam mengenali blind code yang tertera dalam uang kertas rupiah, melalui sebuah 
penelitian. Penelitian dilakukan dengan metode studi kasus deskriptif, dengan jenis kasus tunggal yang ada di lingkungan Sekolah Luar Biasa Negeri A (khusus disabilitas netra) di Kota Bandung merupakan Sekolah bagi disabilitas netra pertama dan tertua di kawasan Asia Tenggara. Adapun sifat kasus yang diteliti bersifat intrinsik yang fokus terhadap kendala yang dialami siswa disabilitas netra dalam mengenali blind code pada uang kertas rupiah.

Teknik pengumpulan data dilakukan dengan cara observasi, focus group discussion, dan simulasi dalam sebuah kegiatan sosialisasi blind code. Data yang berhasil dikumpulkan selanjutnya dianalisis dengan teknik analisis data kualitatif melalui proses koleksi, reduksi, display, dan verifikasi. Selanjutnya, upaya validitas data dilakukan dengan menggunakan triangulasi terhadap sumber data, melalui cross check dan recheck kepada narasumber, dengan cara wawancara, serta penelusuran dokumen penunjang. Adapun narasumber yang dipilih dilakukan secara purposif untuk menentukan narasumber yang dianggap mau dan mampu memberi keterangan yang berkaitan dengan fokus penelitian yang ingin diungkap.

\section{PEMBAHASAN}

\section{Pesan Komunikasi dalam Blind Code}

Berdasarkan data yang diperoleh di lapangan, diketahui sejumlah permasalahan yang dihadapi oleh penyandang disabilitas netra dalam mengenali nominal pada uang kertas rupiah. Data ini diketahui pada tahap observasi saat dilakukan kegiatan sosialisasi blind code kepada siswa-siswi disabilitas netra di SLBN A Kota Bandung. Kegiatan ini dihadiri oleh 42 peserta siswa-siswi tingkat Sekolah Menengah Pertama dan siswa-siswi dari Sekolah Menengah Tingkat Atas, yang juga didampingi oleh sejumlah guru. Guru yang turut mendampingi adalah guru sekolah yang memiliki kondisi disabilitas netra maupun awas (non- disabilitas netra).

Kegiatan yang melibatkan fasilitator dari pihak Bank Indonesia ini, berupaya untuk memberikan pengetahuan mengenai ciri-ciri keaslian dan nominal yang teridentifikasi dalam uang kertas rupiah. Akan tetapi, penekanan informasi terdapat pada blind code. Pada kegiatan tersebut terjadi diskusi dan simulasi yang menghasilkan sejumlah data temuan. Data temuan tersebut mengerucut pada kendala yang dihadapi disabilitas netra dalam mengenali nominal pada uang kertas. Data temuan tersebut dikonfirmasikan kepada sejumlah narasumber melalui wawancara. Adapun data temuan dapat dipetakan sebagai berikut: Pertama, Perbedaan ukuran kertas untuk berbagai nominal pada uang kertas rupiah. Berdasarkan kegiatan diskusi melalui forum tanya jawab, diketahui bahwa salah satu kesulitan yang dirasakan disabilitas netra dalam mengenali nominal uang kertas terletak pada ukuran uang kertas yang relatif sulit dibedakan berdasarkan perbandingan perabaan. Hal ini diungkapkan oleh Edi Ali, peserta kegiatan sosialisasi dan juga salah satu guru pendamping yang menyatakan sebagai berikut:

\footnotetext{
"Saat berupaya mengenali nominal uang kertas, kami merasa kesulitan untuk mengidentifikasi nominal karena saat dilakukan perbandingan ukuran uang kertas, misalnya seratus ribu dengan lima puluh ribu, ukurannya relatif tidak terasa berbeda secara signifikan, sehingga kami kesulitan saat akan melakukan transaksi dalam kondisi cepat. Bisakah ke depannya dirancang pembuatan uang kertas ini, nominal dapat dikenali dari ukurannya?
}

Berdasarkan penelusuran dokumen yang disajikan dalam gambar 1, diketahui bahwa uang kertas pecahan Rp50.000 tahun emisi 2005, memiliki ukuran: panjang $149 \mathrm{~mm}$ lebar 65 $\mathrm{mm}$. Sedangkan uang kertas pecahanRp20.000 tahun emisi 2004 ukuran : panjang $147 \mathrm{~mm}$ lebar 65 mm (Bank Indonesia, 2010). Apabila mengacu pada pernyataan narasumber disebutkan bahwa perbedaan ukuran sebesar 2 mm yang dimiliki oleh kedua pecahan uang kertas tersebut dianggap tidak signifikan saat dilakukan perabaan. Artinya, perbedaan $2 \mathrm{~mm}$ di antar kedua pecahan uang kertas tersebut masih memungkinkan untuk diidentifikasi secara visual, tetapi jika diidentifikasi melalui perabaan, maka perbedaan tersebut menjadi tidak terasa, terutama jika kondisi uang kertas mengalami penurunan kondisi, misalnya lusuh. 

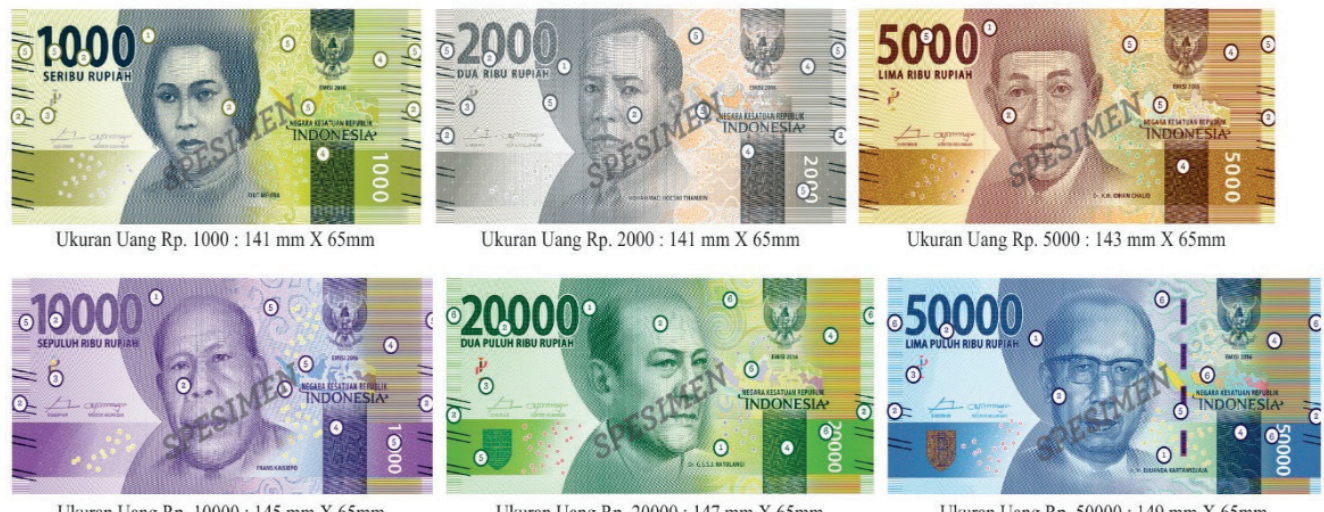

Ukuran Uang Rp. 20000 : 147 mm X 65mm

Ukuran Uang Rp. 50000 : 149 mm X 65mm

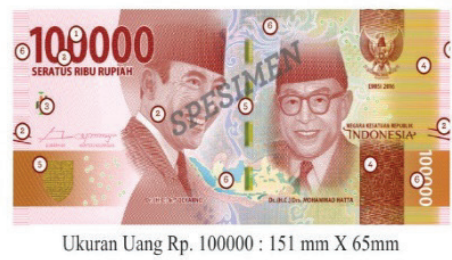

Gambar 1

Ukuran Uang Kertas Tahun Emisi 2016

(Sumber :https://www.bi.go.id/id/rupiah/uangrupiah/Pages/Ciri_Uang_TE_2016.aspx)

Kedua, Kondisi jenis uang kertas rupiah. Kondisi jenis uang kertas rupiah, dinilai oleh narasumber sebagai jenis kertas yang mudah lusuh. Kondisi lusuhnya uang kertas rupiah yang beredar di masyarakat disinyalir diakibatkan oleh pola perawatan uang kertas yang dilakukan oleh sebagian besar masyarakat, belum baik. Seperti yang dikemukakan oleh Cahya Nurdin, fasilitator dalam kegiatan sosialisasi blind code pada uang kertas, berikut ini:

"Jenis kertas yang digunakan untuk membuat uang kertas rupiah merupakan jenis kertas berkualitas baik, begitu juga dengan bahan warna, dan material lain yang digunakan pada proses produksinya. Sehingga biaya produksi uang kertas rupiah sesungguhnya cukup tinggi. Sayangnya, masih banyak masyarakat yang belum mampu memperlakukan uang kertas dengan baik. Uang kertas rupiah masih banyak diperlakukan dengan cara dilipat sebelum dimasukkan ke dalam dompet, bahkan diremas sebelum dimasukan ke dalam saku celana. Perlakuan ini mempercepat proses pelusuhan uang kertas rupiah yang beredar di masyarakat".
Kondisi lusuhnya uang kertas rupiah yang dirasakan oleh sebagian disabilitas netra, menyulitkan mereka untuk mengidentifikasi nominal uang kertas. Padahal, Indonesia sebagai negara dengan jumlah disabilitas netra yang pada akhir tahun 2016 diperkirakan mencapai 3,5 juta jiwa ini, telah menyediakan blind code pada uang kertas untuk kemudahan disabilitas netra mengetahui nominal nang. telah menyediakan blind code pada uang kertas untuk kemudahan disabilitas netra mengetahui nominal nang. Akan tetapi, kenyataannya blind code termasuk cukup sulit diakses oleh tunanetra jika uang kertas tidak dalam kondisi baik (Anindita, Novianty, \& Sabril, 2012). Adapun yang dimaksud dengan kondisi uang kertas yang tidak berada dalam kondisi baik, memungkinkan terjadinya pengaburan intaglio (bagian yang terasa kasar saat dilakukan perabaan pada permukaan uang kertas) sebagai penanda blind code yang tertera pada uang kertas rupiah.

Hal ini didukung oleh hasil riset yang menyatakan bahwa meskipun para disabilitas netra memiliki keterbatasan penglihatan, mereka masih dapat mengenali nominal 
uang kertas dengan cara meraba logo timbul pada uang kertas tersebut. Akan tetapi, lamakelamaan dan seringnya uang berpindah tangan akan menyebabkan logo timbul menipis, sehingga menyebabkan tunanetra kesulitan mengenali nominal uang (Radhiyah, Mukhtar, Muhaimin, Kusuma, \& Basuki, 2015). Maka perlu pula dilakukan pemberian informasi cara memperlakukan uang kertas agar tidak dilipat, ditulisi, dan dihindarkan dari kondisi basah. Sosialisasi perlu dilakukan secara terus menerus kepada masyarakat, hingga terpolakan menjadi gaya hidup yang ditularkan.

Ketiga, Variasi Blind code pada beberapa emisi. Terdapat perbedaan blind code yang tertera pada uang kertas rupiah untuk emisi tahun 2014 dan 2016. Uang kertas rupiah memiliki beberapa tanda khusus yang dapat dikenali oleh penyandang disabilitas netra. Fitur atau tanda tersebut dapat berupa simbol gambar berbentuk segitiga, lingkaran, dan segi empat yang dicetak timbul sehingga bisa diraba. Penanda tersebut, terdapat pada uang pecahan di atas Rp10 ribu, bentuk lingkaran satu untuk penanda nominal Rp10 ribu, satu segi empat untuk penanda nominal Rp20 ribu, sedangkan dua segitiga untuk penanda nominal Rp50 ribu, dan dua lingkaran untuk penanda nominal Rp100 ribu. Sedangkan untuk uang kertas rupiah untuk emisi tahun 2016, blind code berada di tepi kanan dan kiri uang kertas yang berbentuk garis, seperti yang terlihat pada gambar 2 .

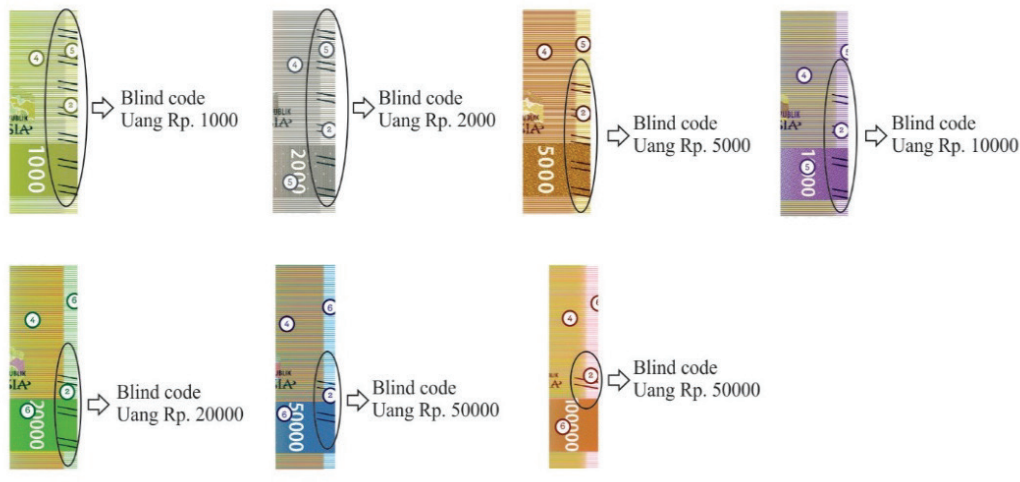

Gambar 2

Blind Code Uang Kertas Emisi 2016

(Sumber : https://www.bi.go.id/id/rupiah/uangrupiah/Pages/Ciri_Uang_TE_2016.aspx)

Meskipun penentuan kode disabilitas netra pada pecahan uang kertas Rupiah ditetapkan oleh Bank Indonesia telah melalui konsultasi dengan PERTUNI (Persatuan Tuna Netra Indonesia) (Bank Indonesia, 2017b). Akan tetapi, perbedaan jenis blind code pada uang kertas yang masih berlaku dan beredar di masyarakat, masih membingungkan disabilitas netra dalam mengenalinya. Pada dasarnya, kelemahan tunanetra dalam mengenali nominal uang kertas dapat menyebabkan tertukarnya uang, salah ambil, bahkan tertipu pada saat melakukan transaksi (Radhiyah et al., 2015). Oleh karena itu, salah satu peserta kegiatan sosialisasi, yaitu Usep, yang sekaligus juga merupakan guru di SLBN A Bandung, sempat megutarakan pernyataan sebagai berikut:

"Kami mengapresiasi pemerintah yang telah berupaya menyediakan blind code pada uang kertas rupiah, namun dengan blind code yang ada sekarang, kami masih merasa kesulitan untuk mengenalinya, apalagi jika kami memperoleh uang kertas dari berbagai emisi yang memiliki perbedaan blind code untuk pecahan uang yang sama. Apakah tidak memungkinkan jika ke depannya blind code itu dibuat dalam bentuk Braille agar kami dapat dengan cepat dan mudah mengenalinya?"

Usulan tersebut disampaikan peserta sosialisasi berkaitan dengan kesulitannya dalam 
mengenali blind code yang dianggap masih sulit diidentifikasi, terutama jika penyandang disabilitas netra hendak melakukan transaksi yang dituntut dapat dilakukan secara cepat. Selain itu usulan penanda berupa Braille diusulkan mengingat Braille dianggap lebih familiar bagi disabilitas netra dibandingkan blind code yng dipakai selama ini, sehingga membutuhkan sosialisasi secara terus menerus, saat ada penggunaan blind code baru.

Keempat, Perabaan Blind code oleh Disabilitas Netra. Pada uang kertas rupiah, pecahan Rp. 20.000 Tahun Emisi (TE) 2004 terjadi perubahan dalam kode tuna netra (blind code), terdapat dua buah empat persegi panjang yang pada emisi sebelumnya tidak kasat mata (invisible) menjadi kasat mata serta akan terasa lebih kasar saat diraba (cetak intaglio). Blind code tersebut terletak di samping kiri pada gambar utama yang terletak di bagian depan uang (Biro Hubungan Masyarakat Bank Indonesia, 2011). Sedangkan pada uang kertas tahun emisi 2016 Kode Tuna Netra (Blind code) Berupa pasangan garis di sisi kanan dan juga kiri pada uang kertas yang akan terasa lebih kasar saat dilakukan perabaan (Tactile) (Bank Indonesia, 2017b).
Diakui oleh hampir seluruh peserta bahwa memang terdapat bagian yang kasar saat dilakukan perabaan pada permukaan uang kertas baru yang dibagikan saat simulasi. Akan tetapi, bagian yang teraba kasar tersebut menjadi berkurang tingkat kekasarannya pada saat diraba pada uang yang tidak baru. Hal ini disebabkan uang kertas rupiah tersebut sudah dalam kondisi lusuh. Rupiah lusuh adalah Rupiah yang secara ukuran dan bentuk fisik tidak mengalami perubahan dari ukuran aslinya, namun kondisinya telah berubah,misalnya karena bahan kimia dari coretan, jamur, ataupun minyak (Bank Indonesia, 2011). Sehingga kualitas perabaan yang dilakukan oleh disabilitas netra pada intaglio penanda nominal yang berbentuk blind code menjadi tidak optimal.

Kelima, Intaglio penanda lain. Pada uang kertas pecahan seratus ribu rupiah tahun emisi 2016, digunakan teknik cetak khusus, yang terdapat pada Gambar Utama, Gambar Lambang Negara "Garuda Pancasila", angka nominal "100000", huruf terbilang "SERATUS RIBU RUPIAH" dan Frasa "NEGARA KESATUAN REPUBLIK INDONESIA" yang akan terasa kasar bila diraba (Bank Indonesia, 2017a). Jenis cetak khusus ini dikenal dengan intaglio.

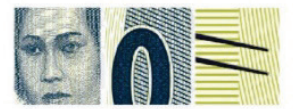

Intaglio Uang Rp. 1000

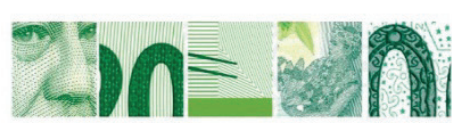

Intaglio Uang Rp. 20000

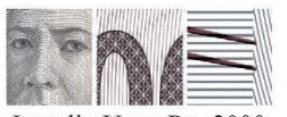

Intaglio Uang Rp. 2000

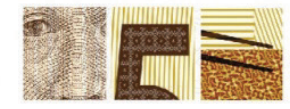

Intaglio Uang Rp. 5000

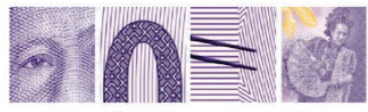

Intaglio Uang Rp. 10000

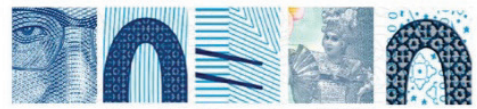

Intaglio Uang Rp. 50000

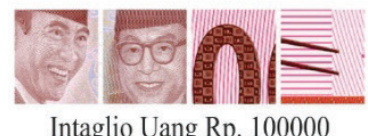

Intaglio Uang Rp. 100000

Gambar 3

Intaglio Uang Kertas Tahun Emisi 2016

(Sumber : https://www.bi.go.id/id/rupiah/uangrupiah/Pages/Ciri_Uang_TE_2016.aspx)

Menurut Bank Indonesia penggunaan gambar-gambar dalam uang Rupiah kertas Tahun Emisi 2016 diharapkan dapat membangkitkan rasa cinta tanah air masyarakat Indonesia (Yonita, Hafiar, \& Sani, 2018). Untuk itu, dapat dipahami alasan di balik penggunaan cetak khusus intaglio untuk menonjolkan beberapa item pada permukaan uang kertas rupiah tersebut, selain dapat digunakan untuk tujuan lain, yaitu untuk mengidentifikasi keaslian uang kertas rupiah melalui teknik perabaan. Hal ini tidak terlepas dari adanya niat baik yang menunjang kesetaraan. Kesetaraan merupakan hasil konstruksi (Nugroho, 2018). 
Semangat kesetaraan yang diniatkan oleh pemerintah sudah semestinya mendapatkan dukungan dari berbagai lapisan masyarakat. Salah satu dukungan masyarakat yang dapat dilakukan secara bertahap adalah dengan membantu menyebarkan informasi yang akurat mengenai cara mengenali nominal dan keaslian uang rupiah kepada orang-orang yang berada di lingkungannya.

Informasi mengenai cara mengenali keaslian uang kertas rupiah telah dilakukan sejumlah kegiatan sosialisasi, antara lain: sosialisasi mengenai ciri-ciri uang rupiah asli untuk mengurangi dan meminimalisir peredaran uang palsu di masyarakat (Agustiyani et al., 2018). Oleh karena itu, salah satu solusi yang diberikan oleh pemerintah kepada masyarakat adalah anjuran untuk lebih berhati-hati terhadap peredaran uang palsu dengan cara 3D (dilihat, diraba dan diterawang). Walau demikian langkah tersebut belum secara akurat dapat membedakan antara uang kertas asli dan palsu. Sehingga perlu diupayakan adanya sebuah sistem deteksi melalui olah citra digital (Umar, Riadi, \& Miladiah, 2018).

Penggunaan intaglio guna mengidentifikasi ciri keaslian dan penanda nominal yang ditujukan bagi aksesibilitas disabilitas netra terhadap uang kertas, ternyata menimbulkan permasalahan tersendiri. Keberadaan intaglio pada beberapa titik penanda dianggap oleh sebagian disabilitas netra sebagai faktor yang dapat mengaburkan konsentrasi untuk fokus mencari penanda nominal pada permukaan uang kertas rupiah.

Keenam, Warna yang relatif mirip. Selain faktor ukuran, jenis kertas dan blind code, hal yang juga membuat kesulitan penyandang disabilitas netra dalam mengenali nominal uang kertas adalah warna yang ada pada uang kertas rupiah. Penyandang hambatan penglihatan terbagi dalam tiga subkelompok: buta warna, sebagian melihat (low vision) dan buta (totally blind). Kebutuhan pertama mereka adalah fitur denominasi yang berguna daripada fitur keamanan, karena mereka membantu mereka dalam menentukan nilai uang kertas (Heij, 2009). Berdasarkan pernyataan tersebut diketahui bahwa informasi mengenai pengenalan nominal uang kertas dianggap lebih penting dari pada informasi mengenai keaslian uang kertas. Hal ini disebabkan kebutuhan akan pemahaman dalam mengenali nominal lebih besar karena intensitas berinteraksi dengan uang kertas yang harus dikenali dengan benar lebih tinggi dibandingkan intensitas interaksi mereka dengan uang palsu yang dianggap perlu diwaspadai.

Bagi penyandang hambatan penglihatan yang termasuk ke dalam kategori low vision, perbedaan warna pada uang kertas rupiah dianggap tidak terlalu membedakan dengan jelas, terutama pada pecahan uang dua puluh ribu dan dua ribu. Hal ini bahkan diungkapkan oleh Yanti, salah satu pendamping kegiatan yang termasuk ke dalam kategori awas.

“Kalo untuk uang dua puluh ribu dan dua
ribu, memang saya sendiri suka sering
tertukar, terutama saat mengeluarkan uang
untuk membayar parkir, yang seharusnya
bayar dua ribu, eh malah jadi memberikan
selembar uang dua puluh ribu, memang
warnanya kalo dua puluh ribu itu hijau,
sedangkan dua ribu berwarna abu-abu,
namun secara sekilas, bagi saya saja yang
awas sering tertukar, apalagi bagi yang
mengalami gangguan penglihatan. Terlebih
angka depannya sama-sama angka dua, dan
jumlah nol kadang berbayang sehingga tidak
jelas jika dilihat secara sekilas. Mungkin
karena mata saya minus juga sehingga
angka nol yang berjejer di belakang angka
dua sering tak bisa cepat terbaca ada tiga
atau empat buah. Tapi kalau untuk uang
lima ribu dan lima puluh ribu, tidak pernah
tertukar. Bisa jadi karena warnanya cukup
jauh berbeda yaitu coklat dan biru”

Pada prinsipnya, warna memberikan informasi yang signifikan dan nilai-nilai penting dalam proses deskripsi objek dan tugas untuk mencocokkan (Saraf, Sindhikar, Sonawane, \& Thakare, 2017). Hal ini juga berlaku dalam proses mengidentifikasi nominal berdasarkan pengetahuan warna yang menjadi kekhasan tiap nominal pada uang kertas rupiah. Oleh karena itu, diperlukan cara untuk mendeteksi nilai nominal uang melalui perbedaan warna di setiap mata uang kertas. 
Seperti halnya penelitian yang menggunakan algoritma jaringan saraf tiruan yang digunakan untuk pengenalan pola warna pada uang kertas. Hasil dari penelitian ini adalah sebuah alat bantu pendeteksi nominal uang kertas yang dapat digunakan oleh disabilitas netra. Adapun hasil riset akan kemampuan program tersebut menunjukkan nilai dengan ratarata keberhasilan pengujian sebesar $90.00 \%$ (Saputra, Susanto, \& Nugraha, 2016).

Ketujuh, Gambar yang relatif mirip. Seperti yang telah dikemukakan sebelumnya bahwa kondisi hambatan penglihatan ada yang mengalami buta warna dan low vision. Bagi keduanya, blind code jarang diperhatikan mengingat mereka merasa masih dapat mengandalkan penglihatan atau sisa penglihatan yang dimiliki dalam mengenali nominal uang kertas. Namun demikian beberapa di antara mereka mengeluhkan kesulitan mengenali nominal uang kertas yang dianggap memiliki gambar yang relatif mirip pada lembaran pecahan uang kertas di emisi tahun 2016, Seperti yang dikemukakan Sani, sebagai salah satu pantia kegiatan berikut ini:.

"Secara sekilas, dalam mengenali nominal
uang, kita cenderung melihat warnanya
dulu, jika tidak yakin baru dilihat gambar
atau angka nominal yang tertera pada
lembar uang kertas tersebut, nah gambar-
gambar yang ada di uang kertas itu kalau
dilihat sekilas memang hampir mirip,
terutama gambar pahlawan, yang paling
mudah dibedakan adalah uang seratus ribu
karena gambar pahlawan ada dua orang
atau uang kertas seribu rupiah, karena
gambar pahlawannya perempuan".

Jika bagi sebagian orang awas saja gambar pahlawan yang tertera pada sebagian nominal uang kertas rupiah dianggap mirip, tentu kemiripan ini juga dirasakan oleh para penyandang hambatan penglihatan yang berada pada kategori buta warna dan low vision dalam mengenali nominal uang kertas rupiah saat melakukan transaksi yang membutuhkan waktu cepat, misalnya membayar atau menerima kembalian uang yang berada dalam posisi antrean panjang.

Sesungguhnya, ada hal yang dapat dilakukan oleh masyarakat dalam membantu disabilitas netra guna mengenali beragam nominal uang yang dimilikinya. Misalnya saat memberikan uang kembalian, atau pun menyerahkan sejumlah uang dengan berbagai pecahan uang kertas kepada disabilitas netra. Cara yang dapat dipakai adalah dengan menyusun nominal uang kertas yang ada. Penyandang disabilitas netra akan lebih dapat mengenali, nominal uang kertas yang dimilikinya, dengan cara mengurutkan letak uang dengan nominal tertinggi dan terendah. Contoh praktisnya adalah meletakkan uang dengan nominal paling besar (misalnya 100.000) di atas telapak tangan mereka. Lalu, letakan kembali uang dengan nominal lebih kecil (misalnya 50.000). Setelah itu, letakan kembali uang dengan nominal yang lebih kecil dari 50.000, yaitu uang dengan nominal 20.000 dan seterusnya hingga uang dengan nominal paling kecil berada di tumpukan teratas (Kartunet, 2012).

Selain menghafal nominal uang kertas yang sedang genggamnya, manakala nominal uang itu telah terurut rapih, penyandang disabilitas netra juga memasukannya ke dalam dompet, secara tersusun, sehingga saat akan mengambil uang, mereka sudah memahami harus mengambil uang pada urutan berapa, sesuai dengan nominal yang mereka maksudkan (Kartunet, 2012). Maka pengetahuan untuk membantu disabilitas netra dalam mengenali nominal uang kertas dapat dilakukan oleh segenap masyarakat, terutama saat bertransaksi dengan disabilitas netra, yaitu membantu mereka mengenali dengan cara menyusun uang kertas saat membayar ataupun memberikan uang kembalian.

Terlepas dari berbagai upaya yang ada, disabilitas netra berharap adanya teknologi yang bersifat user friendly untuk membantu mereka mengenali uang kertas rupiah secara cepat. Sejauh ini, berbagai alat bantu teknologi telah diupayakan untuk dikembangkan demi memudahkan disabilitas netra dalam beraktivitas sehari-hari, misalnya peta elektronik sebagai media informasi bagi tunanetra (Zulfatman., Anadiansyah, \& Nurkasan, 2018), alat bantu berbasis teknologi ini tentu membantu disabilitas netra untuk membaca 
peta yang tak dapat dilakukannya jika disodori peta dalam bentuk kertas seperti pada umumnya. Jika peta yang biasanya dibuat dalam bentuk cetak pada sebuah kertas saja dapat didigitalisasi, tidak mengherankan jika disabilitas netra juga berharap akan adanya teknologi pengenal uang kertas yang dapat membantu mereka mengenali nominal uang kertas rupiah secara cepat dan akurat.

Oleh karena itu, terdapat berbagai riset yang menunjukkan upaya untuk membantu disabilitas netra dalam mengenali nominal uang kertas rupiah yang dilakukan oleh periset dalam negeri, antara lain: metode ekstraksi ciri Local Binary Pattern yang dapat digunakan dalam permasalahan identifikasi pada uang kertas Rupiah (Pratama \& Widiarti, 2016), dan aplikasi scanner nilai mata uang berbasis Android, yang diberi nama Mas Jawa T-Netra (Wahyudin, Yulianti, Indrawan, Pangestika, \& Septiana, 2017). Namun tentu saja keberadaan berbagai aplikasi temuan ini perlu ditindaklajuti efektivitas dan efisiensinya. Sebagai contoh, sebuah aplikasi yang terdapat pada sistem operasi Android dan memiliki fasilitas audio sebagai alat bantu disabilitas netra dalam mengenali nominal uang kertas. Sebuah penelitian pernah melakukan percobaan melalui 14 gambar uang kertas dengan 4 macam jarak yang berbeda. Hasilnya menunjukkan adanya keberhasilan mengenali nominal uang sebesar 73,21\% dan gagal mengenali nominal uang sebesar $26.79 \%$ (Radhiyah et al., 2015).

Perlu disadari bahwa kini disabilitas netra sudah mulai dapat menggunakan aplikasi yang dirancang khusus untuk kondisi mereka, guna melakukan kegiatan seharihari. Sejumlah aplikasi seluler yang dapat digunakan disabilitas netra dianggap cukup membantu dan memuaskan, sehingga mereka berharap adanya peningkatan dan keragaman aplikasi baru. Oleh karena itu, implikasi bagi praktisi pengembang aplikasi, khususnya yang ditujukan bagi penyandang gangguan penglihatan perlu secara terus menerus memperbaiki dan menguji aplikasi yang ada. Praktisi perlu memiliki pengetahuan tentang penggunaan aplikasi sehingga mereka dapat memberikan instruksi yang efektif kepada klien mereka (Griffin-Shirley et al., 2017)those who are blind or have low vision. Banyak aplikasi yang sudah berupaya untuk dikembangkan guna membantu disabilitas netra dalam mengenali uang kertas rupiah, baik dari pengenalan nominal maupun keaslian. Namun selain faktor user friendly yang menjadi tuntutan tambahan, mereka juga membutuhkan sosialisasi keberadaan temuan-temuan tersebut, sehingga hasil temuan tersebut dapat digunakan dan dirasakan manfaatnya secara langsung oleh disabilitas netra.

\section{Komunikasi Pesan melalui Kegiatan Sosialisasi}

Selain temuan aplikasi berbasis teknologi yang diharapkan dapat membantu mempermudah disabilitas netra dalam mengenali uang kertas, kegiatan sosialisasi mengenai blind code kepada disabilitas netra tetap perlu dilakukan secara intensif. Terdapat dua jenis sosialisasi, yaitu sosialisasi primer dan sosialisasi sekunder (Yanuary \& Gumilar, 2018). Adapun sosialisasi adalah proses penanaman nilai dan aturan dari satu kelompok atau masyarakat kepada kelompok atau masyarakat lainnya (Komariah \& Subekti, 2016). Kegiatan sosialisasi dapat digunakan untuk menanamkan nilai-nilai tertentu, yang dapat dilakukan secara sinergis, oleh pihak-pihak yang berkepentingan (Mulyana, Octavianti, \& Bajari, 2019).

Sosialisasi merupakan kegiatan komunikasi publik. komunikasi publik menjadi sarana penyampaian kebijakan pemerintah, dapat berupa program maupun informasi tentang capaian yang disampaikan kepada masyarakat (Ramadani, 2019), sebagai publiknya. Oleh karena itu, setiap lembaga perlu melakukan sosialisasi tentang tujuan kebijakan, dan program yang dibuat oleh lembaga (Putra, 2016) kepada publik sasarannya.

Artinya kegiatan sosialisasi blind code tetap harus dilakukan secara intensif oleh Bank Indonesia kepada masyarakat yang membutuhkan informasi mengenai blind code, terutama bagi masyarakat yang mengalami hambatan penglihatan yang masih tetap 
merasa kesulitan dalam mengenali nominal pada uang kertas rupiah. Selain itu, dalam hal sosialisasi kepada komunikan disabilitas netra sebaiknya disediakan akses informasi dalam bentuk Braille, rekaman audio, ataupun format elektronik (untuk diakses dengan komputer) (Yuhanda, 2016), untuk memudahkan mereka mengakses kembali informasi yang pernah disampaikan.

Sebagai penutup, dalam kasus uang kertas untuk disabilitas netra, jelas bahwa tidak ada solusi yang unik. Setiap negara, termasuk Indonesia, memiliki caranya sendiri untuk mengatasi masalah ini. Dalam praktiknya diharapkan bahwa secara bertahap dapat ditemukan suatu solusi baru yang memberi lebih banyak kesempatan bagi mereka yang tidak memiliki kondisi normal untuk menjalani kehidupan (Kyrychok, 2018), misalnya penemuan-penemuan terbaru baik yang berbentuk teknologi secara fisik, maupun pengembangan kemampuan secara non fisik, yang dapat dilakukan secara bersamasama oleh pemerintah dan masyarakat, demi terciptanya aksesibilitas disabilitas netra dalam mengenali uang kertas rupiah.

\section{SIMPULAN}

Berdasarkan hasil penelitian, diketahui sejumlah kendala yang dialami disabilitas netra dalam mengenali blind code guna mengidentifikasi nominal pada uang kertas rupiah. Kendala tersebut antara lain: Perbedaan ukuran kertas untuk berbagai nominal pada uang kertas rupiah. Hal ini disebabkan perbedaan ukuran di antara uang kertas yang berbeda nominal, berkisar dalam satuan milimeter. Perbedaan dalam satuan milimeter ini dianggap tidak terlalu memudahkan disabilitas netra dalam mengenali perbedaan nominal pada tiap pecahan uang kertas dari aspek ukuran; Jenis kertas yang mudah lusuh, kondisi kebiasaan sebagian besar masyarakat belum menerapkan anjuran pemerintah dalam memperlakukan uang kertas dengan baik, sehingga beresiko mempercepat proses lusuhnya uang kertas rupiah dan berdampak pada sulitnya disabilitas netra mengidentifikasi blind code pada uang kertas rupiah yang dimilikinya.

Selanjutnya, jenis Blind code yang bervariasi pada beberapa emisi tahun yang berbeda, membuat disabilitas netra merasa kesulitan untuk menghapalkan karakter blind code pada beberapa uang kertas. Begitu pula dengan keberadaan Blind code yang kurang tegas saat dilakukan perabaan, terutama jika dihadapkan dengan kondisi uang kertas yang sudah relatif lusuh. Ditambah terdapat beberapa Intaglio penanda lain yang acap kali mengaburkan konsentrasi penyandang disabilitas netra dalam mencari blind code. Selain itu faktor warna dan gambar yang relatif mirip, dianggap mempengaruhi tingkat akurasi pengenalan uang kertas dalam konteks transaksi yang membutuhkan waktu singkat.

\section{DAFTAR PUSTAKA}

Abdullah, N. N., \& Nasionalita, K. (2018). Pengaruh sosialisasi terhadap pengetahuan pelajar mengenai hoax (studi pada program diseminasi informasi melalui media jukrak di SMKN 1 Pangandaran). CHANNEL: Jurnal Komunikasi, 6(1), 120. https://doi.org/10.12928/channel. v6i1.10217

Agustiyani, M., Hafiar, H., \& Novianti, E. (2018). Sosialisasi ciri-ciri keaslian uang rupiah oleh bank indonesia kpw jawa barat dalam mengurangi peredaran uang palsu di perbankan. Komunikasi, XII(02), 97-110.

Anindita, M., Novianty, A., \& Sabril, M. S. (2012). Aplikasi pendeteksi dan pengenalan nominal uang kertas dengan metode learning vector quantization sebagai alat bantu bagi penyandang tunanetra. IT Telkom Journal on ICT, 1(2), 137-144.

Arpianto, R., Priyatman, H., \& Suryadi, D. (2018). Rancang Bangun Alat Identifikasi Nominal Uang Kertas Untuk Tunanetra Berbasis Arduino Mega 2560 Dengan Ouput Suara. 
Jurnal Teknik Elektro Universitas Tanjungpura, 1(1), 105-113.

Bank Indonesia. (2010). Buku Panduan: Ciriciri keaslian dan standar kualitas uang rupiah. Bank Indonesia.

Bank Indonesia. (2011). Buku panduan uang rupiah: Ciri-Ciri Keaslian, Standar Visual Kualitas Rupiah dan Daftar Rupiah yang Dicabut dan Ditarik Dari Peredaran. (E. Setiawan, W. Yuwono, A. S. Pratomo, \& R. Triwahyono, Eds.) (Cetakan ke). Direktorat Pengedaran Uang Bank Indonesia.

Bank Indonesia. (2017a). Booklet: Kenali Uang Rupiah Anda: Tahun Emisi 2016. Jakarta: Bank Indonesia. Retrieved from https://www.bi.go. id/id/rupiah/uangrupiah/Pages/ Booklet-dan-Leaflet-Rupiah-TE2016. aspx

Bank Indonesia. (2017b). Leaflet: Ciri Keaslian Uang Rupiah: Tahun Emisi 2016. Jakarta.: Bank Indonesia. Retrieved from https://www.bi.go.id/ id/rupiah/uangrupiah/Pages / Booklet-dan-Leaflet-Rupiah-TE2016. aspx

Biro Hubungan Masyarakat Bank Indonesia. (2011). Uang Kertas Rupiah Pecahan 20.000, 50.000 dan 100.000 Desain Baru Siap Diedarkan. Retrieved from https://www.bi.go.id/id/ruangmedia/siaran-pers/Pages/Siaran Pers 28102011.aspx

Dunai, L. D., Pérez, M. C., Peris-Fajarnés, G., \& Lengua, I. L. (2017). Euro banknote recognition system for blind people. Sensors, 17(1), 1-14. https://doi. org/10.3390/s17010184

Griffin-Shirley, N., Banda, D. R., Ajuwon, P. M., Cheon, J., Lee, J., Park, H. R., \& Lyngdoh,S.N.(2017). A Survey on the Use of Mobile Applications for People who Are Visually Impaired. Journal of Visual Impairment $\mathcal{E}$ Blindness, July-Augus, 307-323. https://doi. org/10.1177/0145482×1711100402
Hanney, N. M., \& Tiger, J. H. (2012). Teaching Coin Discrimination To Children With Visual Impairments. Journal of Applied Behavior Analysis, 45(1), 167-172. https://doi.org/10.1901/ jaba.2012.45-167

Hasanuzzaman, F. M., Yang, X., \& Tian, Y. (2011). Robust and effective component-based banknote recognition by SURF features. WOCC 2011 - 20th Annual Wireless and Optical Communications Conference, 1-6. $\quad$ https://doi.org/10.1109/ WOCC.2011.5872294

Heij, H. de. (2009). Banknote design for the visually impaired. DNB Occasional Studies, 7(2).

Ikhsan, \& Sari, P. P. (2018). Sistem Pendeteksi Nominal dan Keaslian Uang Kertas Rupiah untuk Penyandang Tuna Netra Berbasis Arduino. Jurnal Ilmiah Informatika, 06(02), 10-15.

Kartunet. (2012). Cara Tunanetra Mengenali Uang. Retrieved July 15, 2019, from https://www.kartunet.com/caratunanetra-mengenali-uang-1017/

Komariah, K., \& Subekti, P. (2016). Penggunaan Media Massa Sebagai Agen Sosialisasi Dinas Kesadaran Masyarakat Akan Pentingnya Imunisasi. PRofesi Humas, 1(1), 1221.

Kyrychok, A. (2018). The Overview Of Investigation In The Field Of Banknote Design For Visually Impaired People. Eureka: Physics and Engineering, (3), 33-41. https://doi. org/10.21303/2461-4262.2018.00639

Mahnun, N. (2012). Media Pembelajaran (Kajian terhadap Langkahlangkah Pemilihan Media dan Implementasinya dalam Pembelajaran). An-Nida', 37(1), 2735.

Miftah, M. (2013). Fungsi, Dan Peran Media Pembelajaran Sebagai Upaya Peningkatan Kemampuan 
Belajar Siswa. Jurnal Kwangsan, 1(2), 95. https://doi.org/10.31800/ jurnalkwangsan.v1i2.7

Mihradi, R. M., \& Siregar, F. M. (2018). Dinamika Problematika Sosial Perlindungan Buruh Migran Indonesia Pasca Reformasi Dan Relevansinya Dengan Tantangan Wirausaha Di Era Masyarakat Ekonomi Asean (Mea). Jurnal Kawistara, 7(2), 179. https://doi. org/10.22146/kawistara.23657

Mulyana, S., Octavianti, M., \& Bajari, A. (2019). Sosialisasi Kebijakan Penghapusan Human Trafficking Di Kabupaten Indramayu. Jurnal Manajemen Komunikasi, 1(1), 95-112. https:// doi.org/10.24198/jmk. v1i1.10063

Nugroho, C. (2018). Relasi Kuasa Media Dan Isu Gender Power Relation And Gender Issue. ProTVF, 2(2), 111-126.

Paisios, N., Rubinsteyn, A., \& Subramanian, L. (2012). Exchanging Cash with no Fear : A Fast Mobile Money Reader for the Blind. Frontiers in Accessibility for Pervasive Computing Manchester UK (Co-Located with PerCom 2012)., 2-5.

Pratama, P. J., \& Widiarti, A. (2016). Identifikasi Nilai Nominal Uang Kertas Dengan Metode Local Binary Pattern. Realtech, 12(2), 1-8.

Purwasito, A. (2017). Analisis Pesan Message Analysis. The Messenger, 9(1), 103109.

Putra, F. A. (2016). Komunikasi Politik Berbasis Kearifan Lokal. Paradigma Madani, 3(2), 33-44.

Radhiyah, A., Mukhtar, I., Muhaimin, A., Kusuma, S., \& Basuki, D. K. (2015). Perangkat Lunak Pengenalan Uang Kertas Sebagai Alat Bantu Tunanetra Dengan Keluaran Audio. Seminar Nasional Sistem Informasi Indonesia, (November), 75-80.
Ramadani, T. (2019). The Implementation of Public Communication Management Policy at Ministry of Energy and Mineral Resources. Jurnal Borneo Administrator, 15(1), 1-18. https:// doi.org/10.24258/jba.v15i1.369

Saputra, I.G.,Susanto,E., \&Nugraha, R. (2016). Implementasi Metode Jaringan Saraf Tiruan (JST) Pada Alat Deteksi Nilai Nominal Uang. EProceedings of Engineering, 3(1), 65-71. Retrieved from https://libraryeproceeding. telkomuniversity.ac.id/index.php/ engineering/article/view/2878

Saraf, S., Sindhikar, V., Sonawane, A., \& Thakare, S. (2017). Currency Recognition System For Visually Impaired. International Journal of Advanced Research and Innovative Ideas in Education (IJARIIE), 3(2), 3264-3269.

Singh,S., Choudhury, S., Vishal, K., \&Jawahar, C. V. (2014). Currency recognition on mobile phones. Proceedings International Conference on Pattern Recognition, 2661-2666. https://doi. org/10.1109/ICPR.2014.460

Tempo. (2018, October 21). Cara Tunanetra Mengenali Keaslian dan Nominal Rupiah. Tempo.Co. Retrieved from https://difabel.tempo.co/ $\mathrm{read} / 1138349$ / cara-tunanetramengenali-keaslian-dan-nominalrupiah

Umar, R., Riadi, I., \& Miladiah, M. (2018). Sistem Identifikasi Keaslian Uang Kertas Rupiah Menggunakan Metode K-Means Clustering. Techno. COM, 17(2), 179-185. https://doi. org/10.33633/tc.v17i2.1681

Wahyudin, Y., Yulianti, E., Indrawan, W., Pangestika, A. D., \& Septiana, A. P. (2017). Sistem Deteksi Nilai Nominal Mata Uang Untuk Tuna Netra Menggunakan Metode Optical. Seminar Nasional Fisika Dan Aplikasinya, 47-54. 
Yanuary, D. A., \& Gumilar, G. (2018). Konstruksi Realitas Wartawan Pikiran Rakyat Mengenai Pengarusutamaan Isu Lingkungan. Jurnal Kajian Jurnalisme, 2(2), 235250. https://doi.org/10.24198/ kj.v2i2.21341

Yonita, L., Hafiar, H., \& Sani, A. (2018). Konstruksi makna nasionalisme pada desain uang rupiah kertas. Wacana, 17(1), 13-28.

Yousry, A., Taha, M., \& Selim, M. M. (2018). Currency Recognition System for Blind people using ORB Algorithm. International Arab Journal of E-Technology, 5(1), 34-40.
Yuhanda, F. (2016). Pemenuhan Aksesibilitas Hak Politik Bagi Difabel Dalam Pemilukada 2015 (Studi tentang Aksesibilitas Difabel dalam pelaksanaan Pemilukada di Kabupaten Sragen. Thesis Universitas Muhammadiyah Surakarta. Retrieved from http://eprints.ums. ac.id/49884/

Zulfatman., Anadiansyah, A., \& Nurkasan. (2018). Peta Elektronik Sebagai Media Informasi Bagi Tunanetra Berbasis Labview dan NI MyRio-1900. JNTETI : Jurnal Nasional Teknik Elektro Dan Teknologi Informasi UGM, 7(1), 122-129. 